\title{
The Mechanisms of HBV-Induced Hepatocellular Carcinoma
}

\author{
Yu Jiang (D) \\ Qiuju Han \\ Huajun Zhao \\ Jian Zhang
}

Institute of Immunopharmaceutical Sciences, School of Pharmaceutical Sciences, Shandong University, Jinan, 250012, Shandong Province, People's Republic of China
Correspondence: Jian Zhang Institute of Immunopharmaceutical Sciences, School of Pharmaceutical Sciences, Shandong University, 44 West Wenhua Road, Jinan, 2500I2, Shandong Province, People's Republic of China

Tel +86-53I-8838378I

Fax +86-53I-88383782

Email zhangj65@sdu.edu.cn

\begin{abstract}
Hepatocellular carcinoma (HCC) is a common malignancy, and the hepatitis $\mathrm{B}$ virus (HBV) is its major pathogenic factor. Over the past decades, it has been confirmed that HBV infection could promote disease progression through a variety of mechanisms, ultimately leading to the malignant transformation of liver cells. Many factors have been identified in the pathogenesis of HBV-associated HCC (HBV-HCC), including HBV gene integration, genomic instability caused by mutation, and activation of cancer-promoting signaling pathways. As research in the progression of HBV-HCC progresses, the role of many new mechanisms, such as epigenetics, exosomes, autophagy, metabolic regulation, and immune suppression, is also being continuously explored. The occurrence of HBV-HCC is a complex process caused by interactions across multiple genes and multiple steps, where the synergistic effects of various cancer-promoting mechanisms accelerate the process of disease evolution from inflammation to tumorigenesis. In this review, we aim to provide a brief overview of the mechanisms involved in the occurrence and development of HBV-HCC, which may contribute to a better understanding of the role of HBV in the occurrence and development of HCC.
\end{abstract}

Keywords: hepatocellular carcinoma, hepatitis B virus, carcinogenic mechanisms, therapy

\section{Introduction}

Liver cancer is predicted to be the sixth most commonly diagnosed cancer and the fourth leading cause of cancer-related deaths worldwide in 2018. Primary liver cancers include hepatocellular carcinoma (HCC), intrahepatic cholangiocarcinoma, and combined carcinoma, with HCC accounting for $75-85 \%$ of cases. ${ }^{1}$ The main risk factors for $\mathrm{HCC}$ include chronic infection with hepatitis $\mathrm{B}$ virus (HBV) or hepatitis $\mathrm{C}$ virus (HCV), aflatoxin-contaminated foodstuffs, heavy alcohol intake, and type 2 diabetes. According to the latest statistics, approximately $50-80 \%$ of HCC cases worldwide are caused by HBV infection. ${ }^{2}$ Various pathogenic factors have also been shown to cooperate with HBV to improve the incidence of HCC.,4

Hepatotropic HBV is a DNA virus with a partly double-stranded relaxed circular DNA (rcDNA). According to the different degrees of the whole HBV genome sequence, HBV can be divided into 10 genotypes (A-J). ${ }^{5}$ The HBV gene mainly encodes four kinds of antigens, namely HBsAg, $\mathrm{HBcAg}, \mathrm{HBeAg}$, and $\mathrm{HBxAg}$, the expression of which has been proven to be related to the occurrence of HCC.

HBV infection can promote hepatocellular carcinogenesis through direct or indirect mechanisms. On the one hand, HBV can increase the instability of the host cell genome and cause epigenetic remodeling of host DNA, resulting in chromosomal 
remodeling and the abnormal expression of oncogenes and tumor suppressor genes by integrating into or inducing mutations in host genes. It can also cause the malignant transformation of liver cells by activating various cancerrelated signaling pathways, regulating cell metabolism, and other mechanisms. On the other hand, the liver microenvironment changes through $\mathrm{HBV}$ infection-induced chronic inflammation, the interaction between the virus and the innate immune cells, and adaptive immune cells, which help the virus evade immune surveillance and promote disease evolution from inflammation to the formation of a tumor. Further research on the mechanisms of HCC induced by HBV infection can provide reliable new methods and new ideas for the prevention, diagnosis, and treatment of HBV-HCC. In this review, the main mechanisms associated with HBV-HCC are described based on the latest research progress in this field.

\section{HBV Structure}

The intact HBV consists of a double envelope and a core granule (Figure 1). The envelope is composed of a lipid bilayer and different proteins. The lipid bilayer contains the $\mathrm{S}$ antigen, as well as the pre-S1 and pre-S2 antigens, which together constitute the large, medium, and small protein forms on the envelope, collectively known as the hepatitis B surface antigen (HBsAg). The surface of the core particle is the true viral capsid, which is composed of the $\mathrm{HBV}$ core antigen $(\mathrm{HBcAg})$. The core particle contains

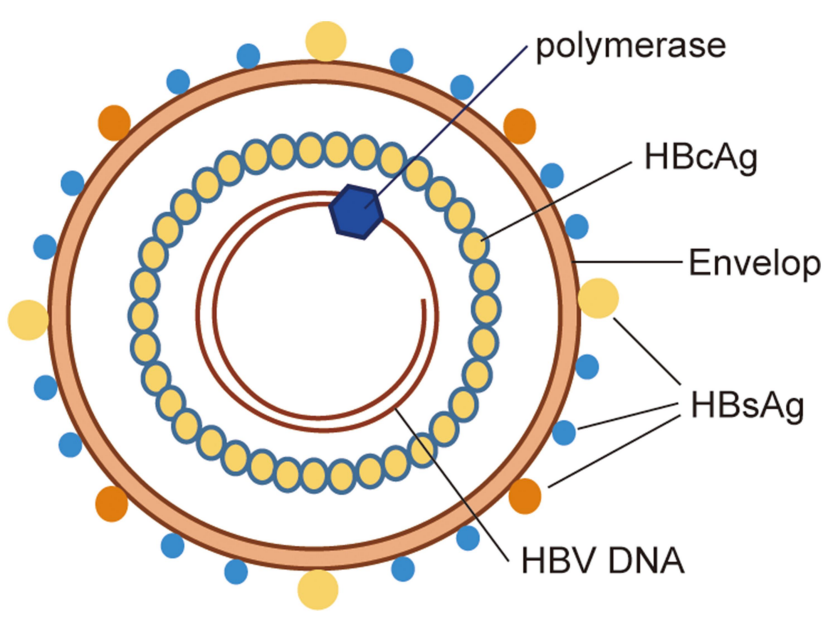

Figure I Schematic representation of HBV structure. The intact HBV consists of a double envelope and a core granule. The lipid bilayer contains the large, medium and small protein forms on the envelope, collectively known as $\mathrm{HBs} \mathrm{Ag}$. The surface of the core particle is the true viral capsid, which is composed of the $\mathrm{HBcAg}$. The core particle contains circular and partially double-stranded DNA and polymerase. Abbreviations: $\mathrm{HBsAg}$, hepatitis $B$ surface antigen; $\mathrm{HBcAg}$, hepatitis $B$ core antigen; HBV, hepatitis $B$ virus. circular and partially double-stranded DNA and polymerase, and is therefore involved in the replication of the HBV genome. In addition, there is also a nucleocapsidrelated soluble $\mathrm{E}$ antigen in the serum called $\mathrm{HBeAg}$.

The HBV genome contains four open reading frames (ORFs), namely ORF-P, -S, -C, and -X. The four ORFs overlap each other, and their regulatory sequences also overlap among them. ORF-P encodes DNA polymerase, reverse transcriptase, and $\mathrm{RNase} H$. It also encodes the terminal proteins that have primase activity. ORF-S consists of the pre-S1, pre-S2, and S genes, which encode the $\mathrm{HBsAg}$ proteins, namely the pre-S1 protein, pre-S2 protein and $\mathrm{S}$ protein, respectively. ORF-C is composed of the pre-C and $\mathrm{C}$ genes, which encode $\mathrm{HBcAg}$ and $\mathrm{HBeAg}$. The $\mathrm{E}$ antigen can be secreted into the serum and participate in the immune regulation of the host. ORF-X encodes the minimum $X$ protein, which has a trans-regulatory function and can activate the enhancers and promoters of homologous or heterologous genes. It is also closely related to the ability of $\mathrm{HBV}$ to infect cells and the occurrence of $\mathrm{HCC}$.

\section{HBV and Gene Mutation}

Mutations in both the HBV gene and somatic genes can promote the malignant transformation of liver cells. Various factors can lead to relevant mutations in the HBV gene, including long-term infection, the special structure of the HBV genome, and the wide, long-term, and non-standard application of NAs (nucleoside/nucleotide analogs), as well as host immune stress, which are conducive to virus survival. Genomic mutations can change the biological behavior and pathogenicity of the virus and are closely related to the malignant transformation of liver disease. Mutations in the HBV genome do not occur randomly throughout the viral DNA, but are often concentrated in specific regions. For example, double mutations in G1896A of the pre-C region and T1762/A1764 in the basal core promoter $(\mathrm{BCP})$ region have been identified as risk predictors of HCC. ${ }^{6}$ Point mutations, deletions, and insertions in the pre-S1 and pre-S2 regions are common in patients with chronic hepatitis B (CHB) and HCC. The mutated pre-S region is more likely to retain the virus in cells, thus promoting the malignant transformation of cells, and is a strong risk factor for the occurrence of $\mathrm{HCC}^{7}$ In patients with cirrhosis and $\mathrm{HCC}$, mutations at specific sites in the $\mathrm{S}$ region lead to premature stop codons. The expression of truncated $\mathrm{S}$ protein can often be detected, which results in the activation of the endoplasmic reticulum stress pathway, induction of DNA oxidative damage, and genomic instability, promoting the formation of 
HCC. In addition, mutations in the HBV can help it evade immune surveillance. It has been demonstrated that the longterm accumulation of epitope mutations in $\mathrm{HBc}$ and $\mathrm{HBe}$ under immune pressure from cytotoxic $\mathrm{T}$ lymphocytes (CTLs) can reduce the virus-specific CTL response, helping viruses evade immune surveillance and disease progression. ${ }^{8-10}$

A large number of somatic mutations occur in the host genome after long-term stimulation of chronic inflammation caused by HBV infection. Some relevant mutations suitable for cell survival will then be screened out and play a significant role in a tumor-promoting effect. Proteogenomic analysis identified five significant mutant genes in tumor tissues of 159 patients with $\mathrm{HBV}$ associated HCC, including TP53 (58\%), CTNNB1 (19\%), Axin1 (18\%), Keap1 (7\%), and RB1 (6\%). ${ }^{11}$ Among them, TP53, Axin1, and RB1 are common tumor suppressor genes, while CTNNB1 is an oncogene. KEAP1 is an important regulatory factor of cell resistance to oxidative stress, and a disorder of the KEAP1-NRF2 pathway is closely related to the induction of drug resistance in malignant tumors. ${ }^{12}$ In addition, it has also been confirmed that many genes, including TERT, ARID1A, ARID2, and NFE2L2, are mutated in HBV-associated HCC. ${ }^{13,14}$ These genes have been shown to be closely related to the occurrence of a variety of malignant tumors, including HCC, ${ }^{15-17}$ which suggests the potential effect of virus infection on somatic cell mutation and the eventual formation of tumors.

\section{HBV DNA Integration}

The integration of viral DNA into the host genome is an important molecular mechanism of HCC occurrence. Although it is not necessary for viral replication, the integration of HBV DNA into the host chromosome has been demonstrated in approximately $85 \%$ to $90 \%$ of tumor cells from patients with HCC. ${ }^{18}$ The integration of HBV DNA into the host genome can result in the rearrangement, partial loss, or acquisition of viral sequences. Although the host gene loci for HBV integration are random, ${ }^{19}$ the integration of HBV DNA into certain genomic loci can enable the integrated cells to acquire the ability of clonal growth, producing more mutations, and promoting malignant transformation. Integration of HBV DNA into host genes is often incomplete, which leads to the destruction of both host and HBV genes, and even the rearrangement of gene sequences, leading to the abnormal expression of oncogenes and tumor suppressor genes. Studies have shown that integration of HBV DNA into host cells can result in significantly high copy number variation (CNV) of chromosomes near the integration sites, causing hepatic cell genome instability and inducing mutations, chromosomal deletions, and gene rearrangements. ${ }^{20,21}$ Therefore, exploring the priority integration regions in the $\mathrm{HBV}$ genome and priority integration sites in the human genome is an important molecular basis for understanding the occurrence of HCC.

With the development of sequencing techniques, the detection of HBV DNA integration is no longer limited to traditional PCR-based detection methods. ${ }^{22} \mathrm{HBV}$ integration in patients with $\mathrm{HCC}$ was analyzed based on $\mathrm{HBV}$ probes and high-throughput sequencing, and showed that integration breakpoints can be distributed in all gene regions of the virus. HBV DNA sequences integrated into the host genome include the $\mathrm{X}, \mathrm{C}$, enhancer, and $\mathrm{S}$ genes, among which the $\mathrm{X}$ and $\mathrm{C}$ genes are the most common integration genes in the genomes of patients with HCC. ${ }^{23} \mathrm{X}$ gene integration can directly activate oncogenes (such as Myc, Ras, Src, and CyclinD1) and inhibit the expression of tumor suppressor genes (such as P53 and $\mathrm{Rb}$ ), thus participating in the occurrence of HCC. C-terminal truncated $\mathrm{X}$ protein $(\mathrm{Ct}-\mathrm{HBx})$ expression can promote hepatocyte proliferation and reprogram cell metabolism by inhibiting thioredoxin-interacting protein (TXNIP). ${ }^{24}$ Furthermore, Ct-HBx regulates the transcription of Caveolin-1 and stabilizes LRP6 to maintain the activation of $\beta$-catenin, promote the progression of $\mathrm{HBV}$ associated $\mathrm{HCC},{ }^{25}$ and enhance the invasion and metastasis of HCC cells. ${ }^{26,27}$ In addition, integrated viral DNA can lead to the persistent expression of mutated and truncated $\mathrm{HBx}, \mathrm{HBsAg}$, and $\mathrm{HBcAg}$ proteins. A high expression of these proteins is associated with endoplasmic reticulum and mitochondrial stress responses and may increase the risk of $\mathrm{HCC} .{ }^{28,29}$

By analyzing the tumor and adjacent non-tumor tissues from patients with HCC, HBV DNA fragments were found to be readily integrated into fragile sites (intergene regions, repeat regions, $\mathrm{CpG}$ islands, and telomeres) and functional regions (including genes related to cell survival, metabolism, and cell cycle regulation) of the host genome. The carcinogenicity of HBV integration depends to some extent on the function of the host genes targeted by HBV in $\mathrm{HCC}^{30}$ Repeated HBV integration can be detected in many tumor-associated genes. Integration hotspots such as TERT, MLL4, CCNA2, CCNE1, and FN1 were previously detected through whole genome sequencing (WGS). Using high-throughput viral integration detection (HIVID) technology, it has been found that HBV integration also exists in many new genes such as NRG3, UNC5D, CTNND2, 
PTPRD, and AHRR, which are closely related to tumor progression. ${ }^{31,32}$ The targeted genes for HBV integration have also been shown to be significantly enriched in cancer-related pathways, such as MAPK, extracellular matrixreceptor interactions, and Hedgehog signaling, and the integration frequency of $\mathrm{HBV}$ is expected to increase along with the progression from hepatitis B to HCC. ${ }^{33}$ The most common HBV integration site occurs in the telomerase reverse transcriptase gene (TERT). The HBx gene promoter, $\mathrm{C}$ gene promoter, and enhancer have been found to integrate into the TERT or nearby regulatory regions. ${ }^{34}$ Repeated integration of the promoter augments the expression of TERT. ${ }^{35}$ Reactivated telomerase can trigger the clonal proliferation of cells, leading to a malignant transformation and the eventual development of HCC. ${ }^{36}$ Recent studies have shown that the binding of E74-like ETS transcription factor 4 (ELF4) to chimeric HBV EnhI in the TERT promoter region is the molecular mechanism of $\mathrm{HBV}$ integration-mediated telomerase activation. ${ }^{37}$

It is worth noting that HBV DNA integration has been found in approximately $70 \%$ of HCC patients with occult HBV infection (OBI) in recent years, mainly involving the virus $\mathrm{X}$ and $\mathrm{preS} / \mathrm{S}$ genomic regions. ${ }^{38,39} \mathrm{HBV}$ DNA gene integration is associated with changes in tumor suppressor genes, mutations in the p53 gene, and genomic instability in HCC patients with OBI. ${ }^{40,41}$ This is also an important reason why patients with OBI tend to develop HCC.

\section{HBV and microRNA}

In recent years, a large number of studies have shown that miRNAs play an important role in $\mathrm{HBV}$ replication as well as in the occurrence and development of HBV-associated HCC. Various miRNAs can promote HBV replication via different mechanisms. ${ }^{42-45}$ Our previous studies revealed that HBV could target RIG-I and RIG-G and inhibit STAT1 expression by inducing miR-146a expression, impairing the clearance of the virus via the innate immune system. ${ }^{46,47}$ By analyzing the global miRNA expression profiles in HBV-associated HCC, it was found that the expression of many miRNAs, such as miR-150 and miR-342-3p, was altered. ${ }^{48,49}$ Analysis of a large number of clinical samples showed that miRNAs such as miR-375, miR-25, and let-7f could be used as HBVspecific miRNAs, showing potential clinical value for the prediction and diagnosis of $\mathrm{HBV}^{+} \mathrm{HCC}{ }^{50,51}$ MiRNAs have also been demonstrated to be closely related to chemotherapy resistance in HBV-associated HCC. ${ }^{52}$ Moreover, HBV can further target different oncogenes ${ }^{53}$ or intervene in multiple signaling pathways, such as Wnt, MAPK, STAT, P53, Akt and Notch, by regulating the expression of different miRNAs to promote $\mathrm{HCC}^{48,54,55}$ (Figure 2). The structural proteins of HBV can also regulate the expression of some miRNAs in a transcription factor-dependent manner, thus regulating the progress of HCC. For example, HBx promotes the expression of miR-1269b in an NF- $\mathrm{kB}$-dependent manner, promoting the proliferation and migration of $\mathrm{HCC}$ cells. ${ }^{56} \mathrm{HBx}$ also interacts with c-Myc to inhibit miRNA-192-3p expression and promote $\mathrm{HBV}$ replication. ${ }^{57}$

In addition to miRNAs expressed by host cells, in recent years, HBV has also been found to encode miRNAs to promote the disease process. In HBV-associated HCC, HBVmiR-2 can act as an oncogene, inhibit cell apoptosis, promote cell growth, and enhance the migration and invasion ability of HCC cells. Moreover, HBV-miR-2 can be detected in both the tissues and sera of patients with $\mathrm{HBV}^{+} \mathrm{HCC}{ }^{58} \mathrm{HBV}-\mathrm{miR}$ -3 controls viral replication in host cells ${ }^{59}$ and promotes $\mathrm{HCC}$ growth by regulating the expression of the host gene protein phosphatase 1A (PPM1A). ${ }^{60}$ HBV-miR-3 can also affect disease progression caused by persistent HBV infection by inhibiting SOCS5, activating the STAT1-IFN signaling pathway, and inducing the M1 polarization of macrophages. ${ }^{59}$

Conversely, in addition to the above promoting effects, some miRNAs have also been found to exert inhibitory effects on HBV-associated HCC processes. HBX-LINE1 integrated in $\mathrm{HBV}^{+} \mathrm{HCC}$ can downregulate miRNA-122 expression, ${ }^{61}$ while ADAR1 can protect against HBV infection by upregulating miRNA-122 in liver cells, ${ }^{62}$ suggesting that miRNA-122 may inhibit the progression of HBV infection to HCC. MiRNA-520a and miR-302c-3p can inhibit $\mathrm{HBV}$ replication and reduce the survival rate of $\mathrm{HBV}^{+}$ HCC cells. ${ }^{63,64}$ Restoration of miR-193b expression increased the sensitivity of $\mathrm{HBV}^{+} \mathrm{HCC}$ to sorafenib. ${ }^{65}$ These phenomena indicate that the role of miRNAs in the progression of HBV-associated HCC is complex but not simply promotive or suppressive, influencing tumor progression by affecting viral replication, or directly promoting or inhibiting the development of tumors.

\section{HBV and Epigenetic Modification}

Recent studies on epigenetic modifications have revealed its key role in cancer development. ${ }^{66} \mathrm{HBV}$ can cause epigenetic remodeling by changing the methylation state of DNA and the post-translational modification of histones, which is an important pathogenesis mechanism of HBV-associated HCC. Bioinformatics analysis showed that the methylation levels of tumor tissues from patients with $\mathrm{HBV}$-associated 


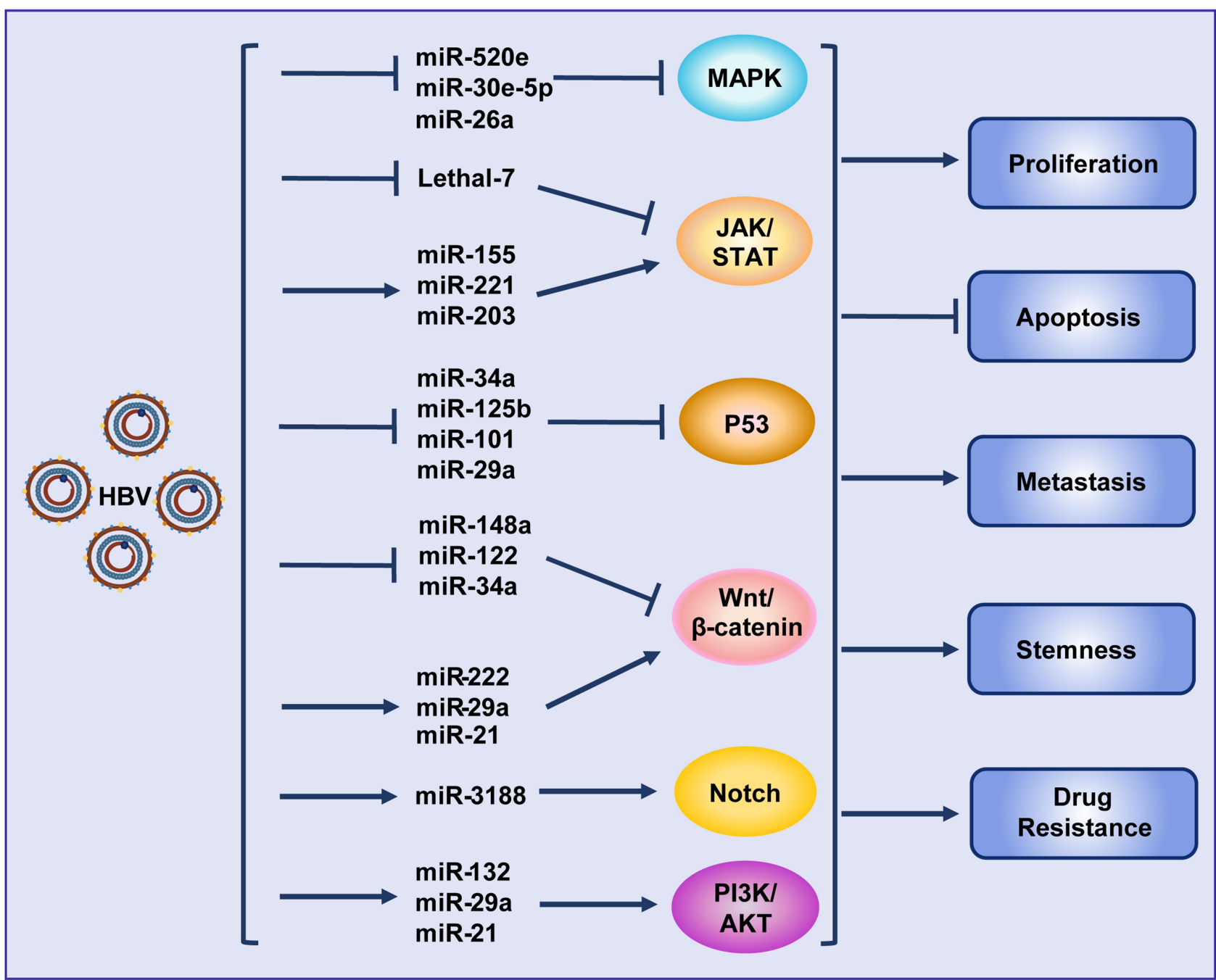

Figure 2 Hepatitis B virus promotes hepatocellular carcinoma by intervening various signal pathways through different microRNAs. Lines ending with arrows or bars indicate promotion or inhibitory effects, respectively.

Abbreviation: HBV, hepatitis B virus.

HCC were significantly higher than those from non-infected HCC patients, where $68 \%$ of the methylated genes were associated with cancer development, ${ }^{67}$ suggesting that HBV infection may affect gene methylation in tumor tissues. The expression of HBV structural proteins (mainly $\mathrm{HBx}$ ) can cause abnormal epigenetic remodeling, activating oncogenes and silencing tumor suppressor genes. ${ }^{66,68} \mathrm{In} \mathrm{HBV}^{+} \mathrm{HCC}$, HBx downregulates the expression of ASPP1 and ASPP2 genes through DNA methylation modification, and dampens their interaction with the p53 protein, which inhibits HCC apoptosis, promotes HCC growth, and is closely related to the occurrence of early liver cancer. ${ }^{69} \mathrm{HBx}$ can also promote the binding of methyltransferases DNMT1 and DNMT3A to the gene promoters of SFRP1 and SFRP5, leading to the silencing of SFRP1 and SFRP5, promoting tumor progression. Inhibition of DNMT1 can inactivate Wnt signaling and reduce the expression levels of the Wnt target genes C-Myc and CyclinD1, impeding the growth and invasion of HBVassociated $\mathrm{HCC}$ in vitro and in vivo. $\mathrm{HBx}$ protein can also stabilize WDR5 (a core subunit of histone H3 lysine 4 methyltransferase) by inhibiting its ubiquitination, promoting the methylation modification of target gene promoters and promoting the formation and growth of tumors in HCC tumor-bearing mice. Moreover, WDR5 can also promote HBV transcription through H3K4Me3 methylation modification of HBV cccDNA. ${ }^{70}$ In addition to methylation modification, the expression of histone deacetylase HDAC1 was significantly increased in the tumor tissues of patients with $\mathrm{HBV}^{+} \mathrm{HCC}$. Furthermore, it was found that $\mathrm{HBx}$ upregulates metastasis-associated protein 1 (MTA1) and HDAC1 at the transcriptional level, which stabilizes HIF- $1 \alpha$ and promotes $\mathrm{HCC}$ invasion and metastasis in HBx-transgenic mice. ${ }^{71}$ 
These phenomena indicate that epigenetic remodeling of $\mathrm{HBV}$ is very important for the pathogenesis of HCC.

In addition, epigenetic mechanisms are involved in the regulation of $\mathrm{HBV}$ replication. The presence of $\mathrm{HBV}$ cccDNA is an important reason for the difficulty in curing HBV infection. The acetylation of histones binding to cccDNA in HCC can promote the transcription of cccDNA at the epigenetic level, thereby promoting HBV replication. By interacting with IncRNA-DLEU2, HBx can regulate viral cccDNA transcription, viral replication, and host cancerrelated gene expression at the epigenetic level. ${ }^{72}$

\section{HBV Involved in Activation of Tumor-Promoting Signaling \\ Pathways}

The carcinogenicity of HBV is closely related to the activation of multiple cancer-related signaling pathways in their host cells (Figure 3). The above described HBV mutations and integrations lead to the abnormal expression of multiple molecules in host cells, most of which are located in key locations of oncogenic signaling pathways. HBV structural proteins are also involved in disease progression by regulating multiple signaling pathways through mechanisms such as regulation of miRNAs or epigenetics.

\section{Wnt/ $\beta$-Catenin Pathway}

An abnormal activation of the Wnt/ $\beta$-catenin signaling pathway has been observed in approximately $66 \%$ of patients with HCC. ${ }^{14}$ Various molecules, including the protein components of $\mathrm{HBV}, \mathrm{HCV}$, and HIF can activate the $\mathrm{Wnt} / \beta$ catenin pathway in $\mathrm{HCC}$ cells. ${ }^{73,74}$ The activation of this pathway is closely related to the occurrence, development, stemness, and drug resistance of HCC. ${ }^{75,76}$ For example, HBx interacts directly with MyH9 to activate the $\mathrm{Wnt} / \beta$ catenin/c-Jun signaling pathway, promoting the formation of stemness, metastasis, proliferation, and sorafenib resistance in $\mathrm{HCC}^{77} \mathrm{HBx}$ competitively binds to APC and replaces the degradable complex of $\beta$-catenin, which causes the accumulation of $\beta$-catenin in the nucleus and activates Wnt signaling, promoting malignant cell transformation. ${ }^{78}$ As mentioned above, HBV can maintain the activation of $\beta$ catenin through a variety of mechanisms, and is closely related to the expression of downstream cyclin D1 and c-Myc. In addition, activated $\beta$-catenin can also interact with other transcription factors, such as TCF and HIF-1 $\alpha$, to regulate the expression of target genes and promote disease progression. ${ }^{79}$

\section{PI3K/AKT Pathway}

The PI3K/Akt pathway is involved in the control of cell growth and proliferation and is abnormally activated in different tumors. ${ }^{80}$ As a tumor suppressor, PTEN can negatively regulate the PI3K/Akt pathway, while HBx can regulate liver cell proliferation and aggravate HBV-related carcinogenesis by inhibiting PTEN and activating Akt. ${ }^{81-83} \mathrm{HBx}$ and Akt also regulate cell proliferation and malignant transformation through a synergistic effect. ${ }^{84}$ The HBx mutant K130M/V131I also promotes HCC formation by activating Akt signaling in a transgenic mouse model.$^{85}$ Akt signaling is also involved in the regulation of HBV transcription and replication. ${ }^{63}$

\section{MAPK Pathway}

MAPK signaling plays an important role in HBV replication, immune escape, and the promotion of tumor cell survival and drug resistance. In HBV-infected cells, p38 MAPK plays a crucial role in $\mathrm{HBsAg} / \mathrm{HBeAg}$ secretion, viral replication, and the formation of HBV cccDNA. ${ }^{86,87}$ In the presence of $\mathrm{HBV}, \mathrm{HBx}$ induced the expression of pro-oncogenic MAPK14 and promoted tumorigenesis, while the inhibition of MAPK14 can largely reverse the HBV-induced resistance of HCC cells to sorafenib. ${ }^{88} \mathrm{HBx}$ relieves the inhibition of ERK by activating Notch signaling, which promotes the growth of $\mathrm{HCC}{ }^{89} \mathrm{HBcAg}$ induces the upregulation of B7-H1 through the activation of the Akt, ERK, and P38 signaling pathways, which inhibits the clearance of HBV DNA and promotes the apoptosis of dendritic cells, ${ }^{90}$ thereby benefiting HBV to evade immune surveillance.

\section{Oxidative Stress Pathways}

Oxidative stress plays an important role in tumor occurrence and development. Reactive oxygen species (ROS) levels are increased in the liver and blood of patients infected with $\mathrm{HBV}$, which are related to the severity of the disease and the replication status of HBV. ${ }^{91-93}$ The structural proteins $\mathrm{HBV}, \mathrm{HBx}, \mathrm{HBS}$, and $\mathrm{HBC}$ can also induce ROS production. ${ }^{94}$ For example, HBx can destroy mitochondrial membrane potential and induce ROS production by interacting with the mitochondrial outer membrane or affecting the respiratory complex. ${ }^{95,96}$ ROS have been shown to play a direct promoting role in HBVinduced liver fibrosis and liver cancer. ${ }^{97,98}$ The KEAP1/ NRF2/ARE pathway plays an important role in antioxidation and resistance to ROS-induced damage. ${ }^{99}$ In 


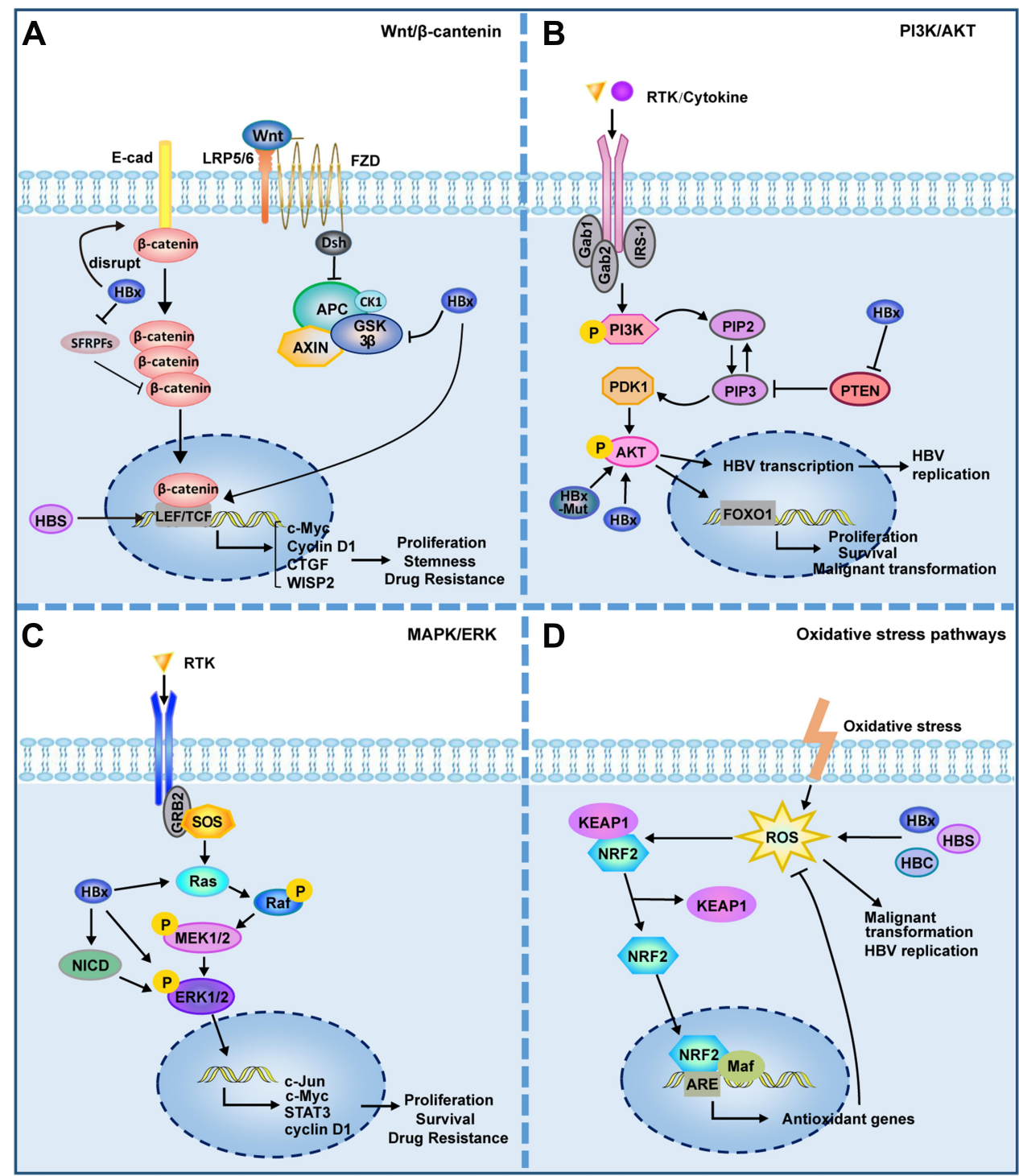

Figure $3 \mathrm{HBV}$ is involved in activation of cancer-related signaling pathways. (A) Wnt/ $\beta$-catenin signalling pathway. HBV can activate Wnt/ $\beta$-catenin signaling by activating TCF or inhibiting GSK3 $\beta$; HBx can silence the SFRPs to activate Wnt signaling; HBx promotes the disintegration of the E-cadherin complex with $\beta$-catenin; HBsAg can upregulate the expression of LEF-I. (B) PI3K/AKT signalling pathway. HBx can inhibit PTEN, a suppressor of PIP3; HBx and HBx mutant can activate Akt directly. (C) MAPK/ ERK signalling pathway. $\mathrm{HBx}$ can activate Ras and ERK directly; $\mathrm{HBx}$ can activate ERK by activating Notch signal. (D) Oxidative stress pathways. The structural proteins of $\mathrm{HBV}, \mathrm{HBx}, \mathrm{HBS}$ and HBC, can induce ROS production. ROS has been shown to play a direct promoting role in viral replication and malignant transformation. ROS can activate KEAPI/NRF2/ARE pathway, which plays an important role in resistance to ROS. Lines ending with arrows or bars indicate activating or inhibitory effects respectively.

Abbreviations: LEF, lymphoid enhancer-binding factor; LRP, low-density lipoprotein receptor-related protein; TCF, T cell factor; FZD, frizzled; E-cad, E-cadherin; SFRPs, secreted frizzled-related proteins; RTK, receptor protein tyrosine kinase; IRS-I, Insulin receptor substrate I; HBx, hepatitis B X protein; HBx-Mut, HBx mutant; NICD, Notch intracellular domain; ROS, reactive oxygen species; HBC, hepatitis B core antigen; HBS, hepatitis B surface antigen; HBV, hepatitis B virus.

HBV-infected tumor cells, activation of NRF2 can reduce the level of intracellular HBV pGRNA and inhibit viral replication, proving that intervening the expression of NRF2 might be an effective means of antiviral therapy.

\section{HBV and Autophagy}

In chronic infection, HBV can activate autophagy through different pathways, ${ }^{100}$ promoting the replication of $\mathrm{HBV}$ and the formation and release of virus particles, thus aggravating the disease process. ${ }^{101-103}$ For example, HBs can activate autophagy by triggering endoplasmic reticulum stress. ${ }^{104} \mathrm{HBx}$ can enhance autophagy and promote viral replication by binding to PI3KC3 or by activating miR-192-3p-XIAP signaling. ${ }^{105}$ Recent studies have found that although the complete autophagy process can promote $\mathrm{HBV}$ replication, late autophagic degradation will degrade a certain amount of virus and HBsAg, suggesting that autophagy plays a dual role in HBV infection. ${ }^{106,107}$ 
In HCC, the level of autophagy is significantly reduced, and a large number of studies have shown that autophagy can inhibit tumorigenesis. ${ }^{108,109}$ Compared with paracancerous tissues, the expression levels of autophagyrelated genes BECN1 and ATG5 were decreased in the tumor tissues of patients with $\mathrm{HBV}$-associated HCC, accompanied by a reduced level of autophagy. ${ }^{110}$ Activation of autophagy can also selectively degrade cyclin D1 and block the cell cycle in the G1 phase, then inhibit DNA synthesis, cell proliferation, and HCC formation. ${ }^{111}$ In addition to affecting tumor cells, autophagy can also play an anti-tumor role by activating the immune response. HBx-modified tumor cells can act as a vaccine, which can activate $\mathrm{T}$ cell-mediated anti-tumor immune responses targeting $\mathrm{HBx}$-positive $\mathrm{HCC}$ cells by inducing autophagy. These results suggest that autophagy can negatively modulate the tumorigenesis of HBVassociated HCC. ${ }^{112}$ Although a large number of studies have confirmed that the level and role of autophagy changes at different stages of HBV infection, how the mutual regulation of HBV and autophagy affects the disease progression from chronic hepatitis to tumor remains to be further explored.

\section{HBV and Metabolism}

In recent years, metabolic reprogramming has been considered an important mechanism in the development of malignant tumors. The liver is the metabolic site of carbohydrates, fat, and protein. Therefore, the occurrence and development of HCC is closely related to metabolic reprogramming. As a key pathogenic factor of HCC, HBV replication and viral proteins play a crucial role in the metabolic reprogramming of tumor cells and stromal cells. The newest multidimensional gene proteomics study systematically revealed the important role of abnormal liver-specific metabolic pathways in HBV-associated HCC. Multi-omics analysis of paired tumor and adjacent liver tissues from patients with $\mathrm{HBV}$-associated $\mathrm{HCC}$ revealed that more than $80 \%$ of liver-specific genes were downregulated at the protein level. The expression of most proteins in liver-specific metabolic pathways is also significantly reduced in tumors. However, the key enzymes in cholesterol metabolism, ammonia/glutamine metabolism, and those in the glycolysis pathway were upregulated in tumors, accompanied by a significant activation of lipid biosynthesis-related enzymes. ${ }^{11}$ These results indicate that liver-specific metabolic pathways are reprogrammed in HBV-associated HCC and suggest that metabolic changes induced by HBV infection may be involved in the occurrence and development of HCC. HBx protein can promote the survival and stemness of tumor cells by upregulating glycolysis and fatty acid oxidation, resulting in the growth of tumors in mice. ${ }^{113,114} \mathrm{Ct}-\mathrm{HBx}$ can reshape glucose metabolism to promote the progression of HCC. ${ }^{24}$ The liver is an important glycogen storage and metabolic organ. The HBx-HDAC1 complex was found to inhibit the expression of glycogen synthase 2 (GYS2) and regulate glycogen metabolism by interacting with acetylated P53, thus promoting the growth of HCC. ${ }^{115} \mathrm{HBp}$ protein can trigger glycolysis through the FoxO3/miRNA-30b-5p/ MINPP1 signaling axis, enhancing the proliferation and migration of tumor cells. ${ }^{116}$

In addition to its influence on tumor cells, metabolic reprogramming induced by HBV may also play a role in promoting tumorigenesis by affecting the extracellular microenvironment. For example, HBV can help the virus evade innate immune recognition by activating glycolysis, promoting HK activity and lactic acid production, and blocking RLR signaling by inhibiting RIG-I/MAVS interactions. ${ }^{117}$ In livers with chronic HBV infection, amino acid depletion affects protein and nucleotide synthesis in $\mathrm{T}$ cells, which in turn affects the activation and function of these cells. ${ }^{118}$ This may be an important mechanism that promotes the progression of HBVassociated HCC. Currently, studies on specific HBVassociated mechanisms of metabolic reprogramming that are involved in the occurrence and development of HCC are still limited. Whether every structural protein of HBV can directly or indirectly regulate the key molecules in the metabolic pathways and participate in metabolic reprogramming, and whether the key enzymes in metabolic pathways play a tumor-promoting role with their nonmetabolic enzyme activity in HBV-associated HCC, remain to be further explored.

\section{HBV and Intestinal Microbiota}

The intestinal flora plays an important role in human metabolism and physiological functions. Because of the existence of the "liver-gut axis," intestinal flora and their metabolites can also influence the progression of liver disease. Chronic viral infection or cirrhosis remains a major cause of liver cancer. The disturbance of intestinal flora was higher in patients with CHB. ${ }^{119}$ Changes in intestinal flora composition and function in patients with early CHB suggest the potential role of intestinal flora in the progression of CHB. ${ }^{120}$ Changes in intestinal microbiota composition and 
diversity have also been detected in patients with HBVassociated $\mathrm{HCC}$, and these microbiota have been shown to be involved in the regulation of different body functions. ${ }^{120,121}$ As an important pathogen-associated molecular pattern, LPS plays an important role in the progression of liver disease caused by the liver-gut axis. LPS promotes the secretion of inflammatory factors by activating TLR4/ $\mathrm{NF}-\kappa \mathrm{B}$, regulates the responses of hepatocytes, Kupffer cells, and hepatic stellate cells, and then promotes the occurrence of HCC. ${ }^{122}$ Regulating the composition of the intestinal flora has been proposed as an adjunct therapy to reduce bacterial translocation and prevent HCC progression. However, the pathogenesis of $\mathrm{HBV}$-associated chronic liver disease and HCC caused by changes in the intestinal microbiota is still not fully understood.

\section{HBV and Immune Tolerance}

With the development of research, an increasing number of researchers have realized that the occurrence and development of tumors is not only due to the proliferation and malignant transformation of the cells themselves, but that the immunosuppressive microenvironment also plays a decisive role. A variety of stromal cells, including immune cells, form a complex regulatory network with tumor cells, which jointly promote the occurrence and development of malignant tumors.

\section{HBV and Immunosuppressive Microenvironment}

The inhibitory effect of HBV on the innate and adaptive immune cells leads to obstacles in virus recognition and clearance, which aggravates HBV-induced chronic inflammation and promotes the malignant transformation of liver cells (Figure 4). In patients with CHB, HBsAg can inhibit the expression and activation of STAT3 in NK cells, thus significantly inhibiting the activation and function of NK cells. $^{123}$ Impaired NK cells show a defective clearance effect on $\mathrm{HBV}$, which further accelerates the progression of hepatitis to HCC. ${ }^{124,125} \mathrm{HBeAg}$ can further inhibit LPSinduced activation of the NLRP3 inflammasome and production of IL-1 $\beta$ by inhibiting NF- $\kappa$ B phosphorylation and ROS production, which contribute to the formation of HBV-induced immune tolerance. ${ }^{126} \mathrm{HBV}$ can also inhibit the secretion of antiviral cytokines by macrophages and promote the polarization of cells from M1 to M2, which contributes to the establishment and maintenance of viral infection. ${ }^{127} \mathrm{HBcAg}$ can induce the upregulation of B7-H1 and promote the apoptosis of DCs, which helps the immune escape of $\mathrm{HBV}^{90}$ In the course of chronic HBV infection, the expression of PD-1, CTLA-4, CD244, and other inhibitory receptors on virus-specific $\mathrm{CD}^{+} \mathrm{T}$ cells increases, which mediates $\mathrm{T}$ cell depletion. ${ }^{128,129}$ It was also detected that the mitochondrial superoxide content in patients with $\mathrm{CHB}$ was significantly higher than that in healthy and cured infection groups, which correlated with $\mathrm{CD}^{+} \mathrm{T}$ cell depletion. ${ }^{130}$ All these negative HBV-induced immunomodulatory effects contribute to the progression of $\mathrm{CHB}$ to $\mathrm{HCC}$. Interestingly, a high expression of TIGIT was found to maintain $\mathrm{CD}^{+} \mathrm{T}$ cell resistance to $\mathrm{HBV}$ in HBsAg transgenic mice. However, HBsAg vaccination could induce the activation of antigen-specific CTLs in the liver of TIGIT-blocked mice. Notably, the immune responses induced in the process of clearing the virus could lead to liver inflammation, which eventually develops into HCC. ${ }^{131}$ These findings suggest that the immune response plays an important role in the progression of hepatitis to HCC.

The immunosuppressive microenvironment also plays an important role in promoting tumor progression. In patients with HBV-associated HCC, the increased peripheral blood neutrophil/lymphocyte ratio (NLR) and increased number of Foxp $3^{+}$Treg cells were positively correlated with disease progression. ${ }^{132,133}$ TGF- $\beta$-miR -34a-CCL22 signaling can induce Treg cell infiltration and promote $\mathrm{HBV}^{+} \mathrm{HCC}$ metastasis. ${ }^{134}$ Moreover, the imbalance between Th17 and Treg cells is a risk factor for the progression of $\mathrm{HCC}$ in $\mathrm{HBV}$-infected patients. ${ }^{135}$ Compared with patients with chronic hepatitis B or cirrhosis, the expression of PD-1 and TIGIT in peripheral blood $\mathrm{CD}^{+}$and $\mathrm{CD}^{+} \mathrm{T}$ cells is significantly upregulated in patients with HBV-associated HCC and is closely associated with accelerated disease progression and poor prognosis. $^{136}$ The tumor microenvironment of HBVassociated HCC also showed more severe immunosuppression and exhaustion than that of non-virus-associated HCC, ${ }^{137}$ which contributes to the poor prognosis associated with HBV-associated HCC. The specific mechanisms by which HBV regulates the exhaustion of immune cells and promote the formation of an immunosuppressive tumor microenvironment remain to be further explored.

\section{HBV and Extracellular Vesicles}

Extracellular vesicles (EVs), as carriers and transporters, can directly transfer proteins, lipids, and nucleic acids between various cells in the microenvironment and play 


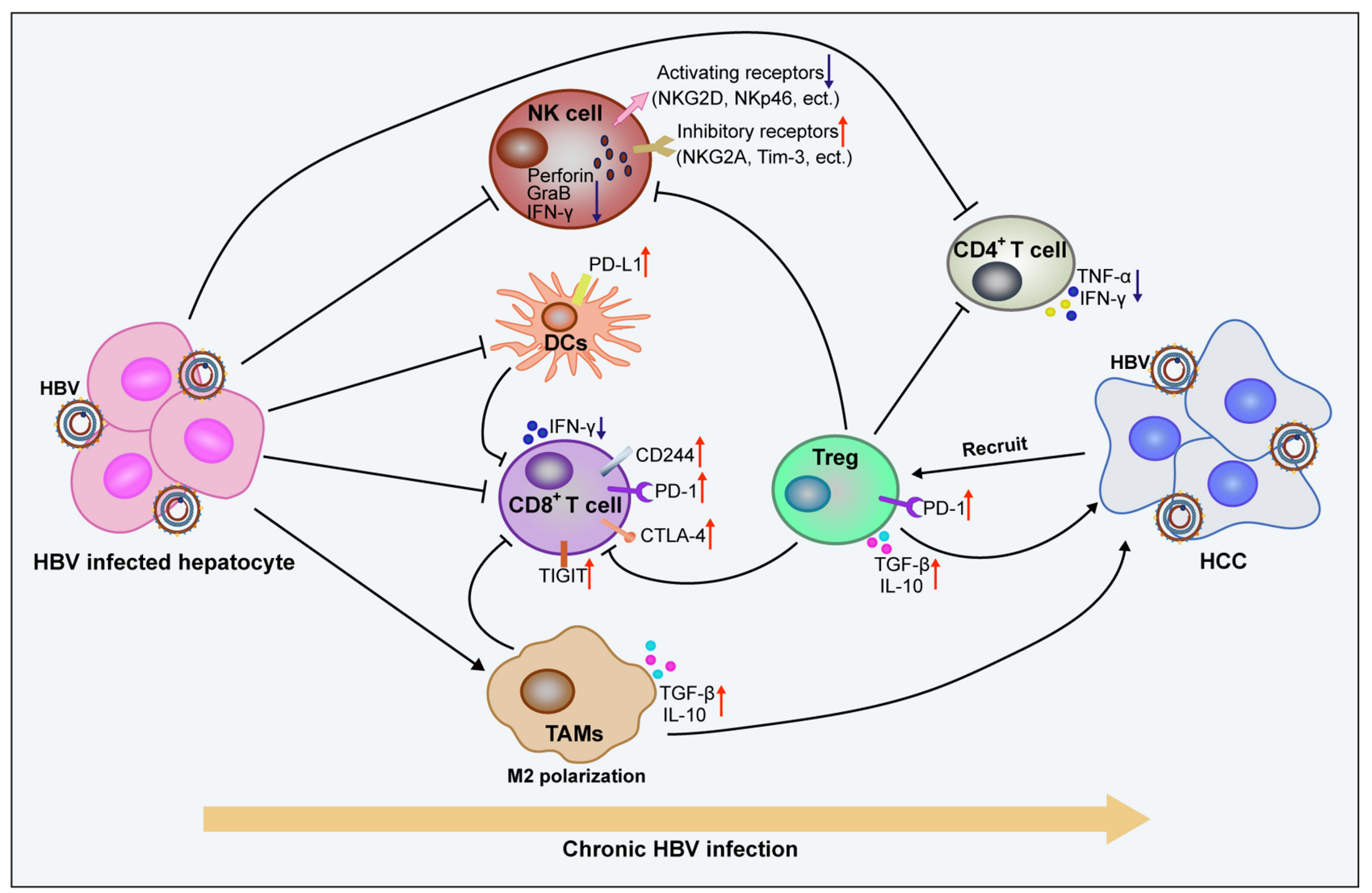

Figure 4 Chronic HBV infection promotes the formation of immunosuppressive microenvironments and promotes the malignant transformation of liver cells. Long lines ending with arrows or bars indicate activating or inhibitory effects respectively. Short arrows pointing up or down indicate up-regulated or down-regulated. Abbreviations: TAMs, tumor-associated macrophages; NK cell, natural killer cell; DCs, dendritic cells; Treg, regulatory T cell; HBV, hepatitis B virus.

an important role in regulating the progression of malignant tumors. The level of miRNAs with negative immunologic modulation roles in EVs secreted by HBV-infected liver cells was increased. These EVs can be taken up by innate immune cells, inhibiting cellular function, and helping the virus resist the host immune response. ${ }^{138,139}$

As an important member of EVs, exosomes play an important regulatory role in HBV-related diseases. ${ }^{138}$ In addition to playing a regulatory role by delivering miRNAs, exosomes secreted by HBV-infected cells contain a variety of HBV RNA, DNA, and protein components. HBx can regulate the biosynthesis of exosomes in the host by increasing the packaging of $\mathrm{HBx}$ mRNA and protein, and delivering them to uninfected liver cells, thereby creating a microenvironment conducive to viral replication. ${ }^{140}$ In HBV transgenic mice, exosomes secreted by HBV-infected cells can also interfere with the clearance of HBVreplicating cells by inhibiting the immune response. HBVpositive exosomes derived from the serum of patients with CHB can be taken up by NK cells, thereby mediating the functional damage of NK cells and inhibiting the antiviral function of NK cells. ${ }^{141}$ These results indicate that exosomes can regulate viral infection, survival, and replication through intercellular communication. In tumor tissues, tumorderived exosomes can transport IFITM2 to DCs, thereby inhibiting the secretion of IFN- $\alpha$ and blocking the antiviral effect of IFN- $\alpha .{ }^{142}$ Exosomes derived from $\mathrm{HBV}^{+} \mathrm{HCC}$ can help tumor cells resist chemotherapy. ${ }^{143}$

\section{Prevention and Treatment}

$\mathrm{HBV}$ is an important pathogenic factor for the occurrence and development of HCC; therefore, the prevention and treatment of viral infection is very important to reduce the incidence and mortality of HBV-associated HCC. Although HBV vaccination can effectively control the spread of the virus, the incidence of hepatitis B has not yet been significantly reduced due to the low vaccination rate among adults. At present, antiviral drugs for CHB include interferon and nucleoside/ nucleotide analogs. Although antiviral therapy can significantly inhibit chronic HBV replication, it does not completely clear HBV with the current therapeutic methods. ${ }^{144}$ 
It has been demonstrated in chronic HBV-infected mice and human $\mathrm{HBV}^{+} \mathrm{HCC}$ that $3 \mathrm{p}-\mathrm{HBx}$-siRNA inhibits viral replication, activates NK and T cells, promotes DC maturation, reduces the proportion of MDSCs, promotes the production of RIG-I-mediated type I interferon and proinflammatory cytokines, and activates the antiviral effect of the innate and adaptive immune systems. ${ }^{145}$ Targeting STAT3 can inhibit viral replication and inhibit proliferation and angiogenesis of $\mathrm{HBV}$-associated HCC, showing a good anti-tumor effect in vivo. ${ }^{123}$ Exosomes have also been shown to mediate the transport of IFN- $\alpha$ from non-infected cells to virus-infected hepatocytes, playing an antiviral role. ${ }^{146,147}$ This suggests that exosomes can act as effective vectors for antiviral therapy. Exosomes can also play an antiviral role as immune adjuvants. ${ }^{148}$

In addition, research on the prevention and treatment of chronic hepatitis B with therapeutic vaccines has also made great progress in recent years. Vaccines based on $\mathrm{HBx}$ can restore the immune response of $\mathrm{HBV}$-specific $\mathrm{CD}^{+}{ }^{+} \mathrm{T}$ cells and $\mathrm{CD}^{+} \mathrm{T}$ cells, showing a good therapeutic effect on chronic HBV infection. ${ }^{149}$ The combined use of Poly I:C as an HBV vaccine adjuvant can overcome the systemic tolerance caused by chronic HBV infection, improve the function of DCs, reverse the exhaustion of HBV-specific $\mathrm{CD} 8^{+} \mathrm{T}$ cells, and induce the formation of long-term immune memory, which can efficiently prevent the recurrence of HBV infections. ${ }^{150}$ More recently, Wang et al designed a dual-targeting HBV pre-S1 nanoparticle vaccine based on ferritin nanoparticles, which can simultaneously target resident SIGNR $1^{+}$macrophages and SIGNR $1^{+}$DCs in mouse lymph nodes, and promote the activation of $\mathrm{B}$ cells and Tfh cells, inducing the production of antibodies. This nanoparticle vaccine induces a high-level and persistent antipreS1 response, which results in an efficient viral clearance and a partial serological conversion in chronic HBV-infected mice, exerting a significant anti-HBV therapeutic effect. ${ }^{151}$

\section{Conclusions}

In conclusion, multiple mechanisms are involved in the regulation of the disease process from HBV infection to tumorigenesis. The occurrence and development of HBV-associated $\mathrm{HCC}$ is a result of the accumulation of multiple factors and the interactions of various mechanisms. With the development of research, new pathogenic mechanisms have been proposed, but there are still many problems that need to be solved. The prevention and treatment of HBV infection is important for the prevention and treatment of HCC. Anti-HBV therapy is still the main treatment for chronic hepatitis B; and although existing antiviral drugs can inhibit HBV replication, they are not effective in clearing HBV, and the incidence of HBVassociated HCC is still high due to repeated viral infection. Raising awareness regarding the importance of hepatitis $B$ vaccination is the most cost-effective means of preventing HBV infection and transmission. New therapies, such as gene therapy and immunoregulatory therapy, are also being studied, but most of these studies are still in the laboratory stage. In terms of stability, drug resistance, and actual efficacy, further evaluation of these therapies is required. Also, further research on the mechanisms of the occurrence and development of HBV-associated HCC is of great significance for us to gain a more comprehensive understanding of the disease process and to find more effective therapeutic targets and strategies to treat HCC.

\section{Acknowledgments}

We are grateful to the Editage (www.editage.cn) for English language editing.

\section{Funding}

This work was supported by the Natural Science Foundation of China (No. 81972694 and 81972686) and the National Major Science \& Technology Project for Control and Prevention of Major Infectious Diseases in China (No.2018ZX10301401).

\section{Disclosure}

The authors report no conflicts of interest in this work.

\section{References}

1. Bray F, Ferlay J, Soerjomataram I, Siegel RL, Torre LA, Jemal A. Global cancer statistics 2018: GLOBOCAN estimates of incidence and mortality worldwide for 36 cancers in 185 countries. CA Cancer J Clin. 2018;68(6):394-424. doi:10.3322/caac.21492

2. Venook AP, Papandreou C, Furuse J, de Guevara LL. The incidence and epidemiology of hepatocellular carcinoma: a global and regional perspective. Oncologist. 2010;15(Suppl 4):5-13. doi:10.1634/theoncologist.2010-S4-05

3. Donato F, Tagger A, Gelatti U, et al. Alcohol and hepatocellular carcinoma: the effect of lifetime intake and hepatitis virus infections in men and women. Am $J$ Epidemiol. 2002;155(4):323-331. doi:10.1093/aje/155.4.323

4. Wild CP, Montesano R. A model of interaction: aflatoxins and hepatitis viruses in liver cancer aetiology and prevention. Cancer Lett. 2009;286(1):22-28. doi:10.1016/j.canlet.2009.02.053

5. Liu CJ, Kao JH. Global perspective on the natural history of chronic hepatitis B: role of hepatitis B virus genotypes A to J. Semin Liver Dis. 2013;33(2):97-102. doi:10.1055/s-0033-1345716

6. Wei F, Zheng Q, Li M, Wu M. The association between hepatitis $\mathrm{B}$ mutants and hepatocellular carcinoma: a meta-analysis. Medicine (Baltimore). 2017;96(19):e6835. doi:10.1097/MD.0000000000006835 
7. Pollicino T, Cacciola I, Saffioti F, Raimondo G. Hepatitis B virus PreS/S gene variants: pathobiology and clinical implications. J Hepatol. 2014;61(2):408-417. doi:10.1016/j.jhep.2014.04.041

8. Zhang Y, Wu Y, Deng M, et al. CD8(+) T-cell response-associated evolution of hepatitis B virus core protein and disease progress. $J$ Virol. 2018;92(17). doi:10.1128/JVI.02120-17.

9. Wu JF, Ni YH, Chen HL, Hsu HY, Chang MH. The impact of hepatitis B virus precore/core gene carboxyl terminal mutations on viral biosynthesis and the host immune response. J Infect Dis. 2014;209(9):1374-1381. doi:10.1093/infdis/jit638

10. Sun L, Zhang Y, Zhao B, et al. A new unconventional HLA-A2restricted epitope from HBV core protein elicits antiviral cytotoxic T lymphocytes. Protein Cell. 2014;5(4):317-327. doi:10.1007/s13238-014-0041-4

11. Gao Q, Zhu H, Dong L, et al. Integrated proteogenomic characterization of HBV-related hepatocellular carcinoma. Cell. 2019;179(2):561-577 e522. doi:10.1016/j.cell.2019.08.052

12. Liu Y, Tao S, Liao L, et al. TRIM25 promotes the cell survival and growth of hepatocellular carcinoma through targeting Keap1-Nrf2 pathway. Nat Commun. 2020;11(1):348. doi:10.1038/s41467-019-14190-2

13. Trung NT, Hoan NX, Trung PQ, et al. Clinical significance of combined circulating TERT promoter mutations and miR-122 expression for screening HBV-related hepatocellular carcinoma. Sci Rep. 2020;10(1):8181. doi:10.1038/s41598-020-65213-8

14. Totoki Y, Tatsuno K, Covington KR, et al. Trans-ancestry mutational landscape of hepatocellular carcinoma genomes. Nat Genet. 2014;46(12):1267-1273. doi:10.1038/ng.3126

15. $\mathrm{Hu} \mathrm{C}, \mathrm{Li} \mathrm{W}$, Tian $\mathrm{F}$, et al. Aridla regulates response to anti-angiogenic therapy in advanced hepatocellular carcinoma. J Hepatol. 2018;68(3):465-475. doi:10.1016/j.jhep.2017.10.028

16. Sun X, Ou Z, Chen R, et al. Activation of the p62-Keap1-NRF2 pathway protects against ferroptosis in hepatocellular carcinoma cells. Hepatology. 2016;63(1):173-184. doi:10.1002/hep.28251

17. Yuan $\mathrm{X}$, Larsson $\mathrm{C}, \mathrm{Xu} \mathrm{D}$. Mechanisms underlying the activation of TERT transcription and telomerase activity in human cancer: old actors and new players. Oncogene. 2019;38(34):6172-6183. doi:10.1038/s41388-019-0872-9

18. Xie Y. Hepatitis B virus-associated hepatocellular carcinoma. $A d v$ Exp Med Biol. 2017;1018:11-21.

19. Brechot C, Gozuacik D, Murakami Y, Paterlini-Brechot P. Molecular bases for the development of hepatitis B virus (HBV)-related hepatocellular carcinoma (HCC). Semin Cancer Biol. 2000;10(3):211-231. doi:10.1006/scbi.2000.0321

20. Sung WK, Zheng H, Li S, et al. Genome-wide survey of recurrent HBV integration in hepatocellular carcinoma. Nat Genet. 2012;44 (7):765-769. doi:10.1038/ng.2295

21. Fujimoto A, Totoki Y, Abe T, et al. Whole-genome sequencing of liver cancers identifies etiological influences on mutation patterns and recurrent mutations in chromatin regulators. Nat Genet. 2012;44(7):760-764. doi:10.1038/ng.2291

22. Matsubara $\mathrm{K}$, Tokino $\mathrm{T}$. Integration of hepatitis $\mathrm{B}$ virus DNA and its implications for hepatocarcinogenesis. Mol Biol Med. 1990;7 (3):243-260.

23. Lee WY, Bachtiar M, Choo CCS, Lee CG. Comprehensive review of Hepatitis B virus-associated hepatocellular carcinoma research through text mining and big data analytics. Biol Rev Camb Philos Soc. 2019;94(2):353-367. doi:10.1111/brv.12457

24. Zhang Y, Yan Q, Gong L, et al. C-terminal truncated HBx initiates hepatocarcinogenesis by downregulating TXNIP and reprogramming glucose metabolism. Oncogene. 2020.

25. Mao X, Tey SK, Ko FCF, et al. C-terminal truncated HBx protein activates caveolin-1/LRP6/beta-catenin/FRMD5 axis in promoting hepatocarcinogenesis. Cancer Lett. 2019;444:60-69. doi:10.1016/j.canlet.2018.12.003
26. Li W, Li M, Liao D, et al. Carboxyl-terminal truncated HBx contributes to invasion and metastasis via deregulating metastasis suppressors in hepatocellular carcinoma. Oncotarget. 2016;7 (34):55110-55127. doi:10.18632/oncotarget.10399

27. Sze KM, Chu GK, Lee JM, Ng IO. C-terminal truncated hepatitis $\mathrm{B}$ virus $\mathrm{x}$ protein is associated with metastasis and enhances invasiveness by C-Jun/matrix metalloproteinase protein 10 activation in hepatocellular carcinoma. Hepatology. 2013;57 (1):131-139. doi:10.1002/hep.25979

28. Choi YM, Lee SY, Kim BJ. Naturally occurring Hepatitis B virus mutations leading to endoplasmic reticulum stress and their contribution to the progression of hepatocellular carcinoma. Int $\mathrm{J} \mathrm{Mol}$ Sci. 2019;20(3). doi:10.3390/ijms20030597

29. Montalbano R, Honrath B, Wissniowski TT, et al. Exogenous hepatitis B virus envelope proteins induce endoplasmic reticulum stress: involvement of cannabinoid axis in liver cancer cells. Oncotarget. 2016;7(15):20312-20323. doi:10.18632/ oncotarget. 7950

30. Li X, Zhang J, Yang Z, et al. The function of targeted host genes determines the oncogenicity of HBV integration in hepatocellular carcinoma. $J$ Hepatol. 2014;60(5):975-984. doi:10.1016/j. jhep.2013.12.014

31. Zhao LH, Liu X, Yan HX, et al. Genomic and oncogenic preference of HBV integration in hepatocellular carcinoma. Nat Commun. 2016;7:12992. doi:10.1038/ncomms12992

32. Li W, Zeng X, Lee NP, et al. HIVID: an efficient method to detect HBV integration using low coverage sequencing. Genomics. 2013;102(4):338-344. doi:10.1016/j.ygeno.2013.07.002

33. Yang L, Ye S, Zhao X, et al. Molecular characterization of HBV DNA integration in patients with hepatitis and hepatocellular carcinoma. $J$ Cancer. 2018;9(18):3225-3235. doi:10.7150/jca.26052

34. D'Souza S, Lau KC, Coffin CS, Patel TR. Molecular mechanisms of viral hepatitis induced hepatocellular carcinoma. World $J$ Gastroenterol. 2020;26(38):5759-5783. doi:10.3748/wjg.v26. i38.5759

35. Toh ST, Jin Y, Liu L, et al. Deep sequencing of the hepatitis $B$ virus in hepatocellular carcinoma patients reveals enriched integration events, structural alterations and sequence variations. Carcinogenesis. 2013;34(4):787-798. doi:10.1093/carcin/bgs406

36. Nault JC, Ningarhari M, Rebouissou S, Zucman-Rossi J. The role of telomeres and telomerase in cirrhosis and liver cancer. Nat Rev Gastroenterol Hepatol. 2019;16(9):544-558. doi:10.1038/ s41575-019-0165-3

37. Sze KM, Ho DW, Chiu YT, et al. Hepatitis B virus-telomerase reverse transcriptase promoter integration harnesses host ELF4, resulting in telomerase reverse transcriptase gene transcription in hepatocellular carcinoma. Hepatology. 2020;73:23-40. doi:10.1002/hep.31231

38. Saitta C, Tripodi G, Barbera A, et al. Hepatitis B virus (HBV) DNA integration in patients with occult HBV infection and hepatocellular carcinoma. Liver Int. 2015;35(10):2311-2317. doi:10.1111/liv.12807

39. Wong DK, Cheng SCY, Mak LL, et al. Among patients with undetectable Hepatitis B surface antigen and hepatocellular carcinoma, a high proportion has integration of HBV DNA into hepatocyte DNA and no cirrhosis. Clin Gastroenterol Hepatol. 2020;18(2):449-456. doi:10.1016/j.cgh.2019.06.029

40. Matsuzaki Y, Chiba T, Hadama T, et al. HBV genome integration and genetic instability in HBsAg-negative and anti-HCV-positive hepatocellular carcinoma in Japan. Cancer Lett. 1997;119 (1):53-61. doi:10.1016/S0304-3835(97)00249-8

41. Mak LY, Wong DK, Pollicino T, Raimondo G, Hollinger FB, Yuen MF. Occult hepatitis B infection and hepatocellular carcinoma: epidemiology, virology, hepatocarcinogenesis and clinical significance. $J$ Hepatol. 2020;73(4):952-964. doi:10.1016/j. jhep.2020.05.042 
42. Chen L, Ming X, Li W, et al. The microRNA-155 mediates hepatitis $B$ virus replication by reinforcing SOCS1 signalling-induced autophagy. Cell Biochem Funct. 2020;38 (4):436-442. doi:10.1002/cbf.3488

43. Dai X, Zhang W, Zhang $\mathrm{H}$, et al. Modulation of HBV replication by microRNA-15b through targeting hepatocyte nuclear factor 1alpha. Nucleic Acids Res. 2014;42(10):6578-6590. doi:10.1093/nar/gku260

44. Jin J, Tang S, Xia L, et al. MicroRNA-501 promotes HBV replication by targeting HBXIP. Biochem Biophys Res Commun. 2013;430(4):1228-1233. doi:10.1016/j.bbrc.2012.12.071

45. Wang Y, Li Y. miR-146 promotes HBV replication and expression by targeting ZEB2. Biomed Pharmacother. 2018;99:576-582. doi:10.1016/j.biopha.2018.01.097

46. Hou Z, Zhang J, Han Q, et al. Hepatitis B virus inhibits intrinsic RIG-I and RIG-G immune signaling via inducing miR146a. Sci Rep. 2016;6:26150. doi:10.1038/srep26150

47. Hou ZH, Han QJ, Zhang C, Tian ZG, Zhang J. miR146a impairs the IFN-induced anti-HBV immune response by downregulating STAT1 in hepatocytes. Liver Int. 2014;34(1):58-68. doi:10.1111/ liv. 12244

48. Wang G, Dong F, Xu Z, et al. MicroRNA profile in HBV-induced infection and hepatocellular carcinoma. BMC Cancer. 2017;17 (1):805. doi:10.1186/s12885-017-3816-1

49. Morishita A, Fujita K, Iwama H, et al. Role of microRNA-210-3p in hepatitis B virus-related hepatocellular carcinoma. Am J Physiol Gastrointest Liver Physiol. 2020;318(3):G401-G409. doi:10.1152/ajpgi.00269.2019

50. Zhu HT, Liu RB, Liang YY, et al. Serum microRNA profiles as diagnostic biomarkers for HBV-positive hepatocellular carcinoma. Liver Int. 2017;37(6):888-896. doi:10.1111/liv.13356

51. Chen S, Chen H, Gao S, et al. Differential expression of plasma microRNA-125b in hepatitis B virus-related liver diseases and diagnostic potential for hepatitis B virus-induced hepatocellular carcinoma. Hepatol Res. 2017;47(4):312-320. doi:10.1111/ hepr. 12739

52. Li R, Xu T, Wang H, et al. Dysregulation of the miR-325-3p/ DPAGT1 axis supports HBV-positive HCC chemoresistance. Biochem Biophys Res Commun. 2019;519(2):358-365. doi:10.1016/j.bbrc.2019.08.116

53. Sadri Nahand J, Bokharaei-Salim F, Salmaninejad A, et al. microRNAs: key players in virus-associated hepatocellular carcinoma. J Cell Physiol. 2019;234(8):12188-12225. doi:10.1002/jcp. 27956

54. Tian JH, Liu WD, Zhang ZY, et al. Influence of miR-520emediated MAPK signaling pathway on HBV replication and regulation of hepatocellular carcinoma cells via targeting EphA2. J Viral Hepat. 2018.

55. Lou W, Liu J, Ding B, et al. Identification of potential miRNA-mRNA regulatory network contributing to pathogenesis of HBV-related HCC. J Transl Med. 2019;17(1):7. doi:10.1186/ s12967-018-1761-7

56. Kong XX, Lv YR, Shao LP, et al. HBX-induced MiR-1269b in NF-kappaB dependent manner upregulates cell division cycle 40 homolog (CDC40) to promote proliferation and migration in hepatoma cells. J Transl Med. 2016;14(1):189. doi:10.1186/ s12967-016-0949-y

57. Wang J, Chen J, Liu Y, et al. Hepatitis B virus induces autophagy to promote its replication by the axis of miR-192-3p-XIAP through NF kappa B signaling. Hepatology. 2019;69 (3):974-992. doi:10.1002/hep.30248

58. Yao L, Zhou Y, Sui Z, et al. HBV-encoded miR-2 functions as an oncogene by downregulating TRIM35 but upregulating RAN in liver cancer cells. EBioMedicine. 2019;48:117-129. doi:10.1016/ j.ebiom.2019.09.012
59. Zhao X, Sun L, Mu T, et al. An HBV-encoded miRNA activates innate immunity to restrict $\mathrm{HBV}$ replication. $J$ Mol Cell Biol. 2020;12(4):263-276. doi:10.1093/jmcb/mjz104

60. Chavalit T, Nimsamer P, Sirivassanametha K, et al. Hepatitis B virus-encoded microRNA (HBV-miR-3) regulates host gene PPM1A related to hepatocellular carcinoma. Microrna. 2020;9 (3):232-239. doi:10.2174/2211536608666191104105334

61. Liang HW, Wang N, Wang Y, et al. Hepatitis B virus-human chimeric transcript $\mathrm{HBx}-\mathrm{LINE} 1$ promotes hepatic injury via sequestering cellular microRNA-122. J Hepatol. 2016;64 (2):278-291. doi:10.1016/j.jhep.2015.09.013

62. Sartorius B, Makarova J, Sartorius B, et al. The regulatory role of microRNA in Hepatitis-B Virus-Associated Hepatocellular Carcinoma (HBV-HCC) pathogenesis. Cells. 2019;8(12):1504. doi: $10.3390 /$ cells 8121504

63. Sun W, Zhang J, Chen J. MicroRNA-520a suppresses HBV replication in HepG2.2.15 cells by inactivating AKT. $J$ Int Med Res. 2018;46(11):4693-4704. doi:10.1177/0300060518792780

64. Hamada-Tsutsumi S, Naito Y, Sato S, et al. The antiviral effects of human microRNA miR-302c-3p against hepatitis B virus infection. Aliment Pharmacol Ther. 2019;49(8):1060-1070. doi:10.1111/apt.15197

65. Mao K, Zhang J, He C, et al. Restoration of miR-193b sensitizes Hepatitis B virus-associated hepatocellular carcinoma to sorafenib. Cancer Lett. 2014;352(2):245-252. doi:10.1016/j. canlet.2014.07.004

66. Flavahan WA, Gaskell E, Bernstein BE. Epigenetic plasticity and the hallmarks of cancer. Science. 2017;357:6348. doi:10.1126/ science.aal 2380

67. Song MA, Kwee SA, Tiirikainen M, et al. Comparison of genome-scale DNA methylation profiles in hepatocellular carcinoma by viral status. Epigenetics. 2016;11(6):464-474. doi:10.1080/15592294.2016.1151586

68. Park IY, Sohn BH, Yu E, et al. Aberrant epigenetic modifications in hepatocarcinogenesis induced by hepatitis $\mathrm{B}$ virus $\mathrm{X}$ protein. Gastroenterology. 2007;132(4):1476-1494. doi:10.1053/j. gastro.2007.01.034

69. Zhao J, Wu G, Bu F, et al. Epigenetic silence of ankyrin-repeatcontaining, SH3-domain-containing, and proline-rich-regioncontaining protein 1 (ASPP1) and ASPP2 genes promotes tumor growth in hepatitis B virus-positive hepatocellular carcinoma. Hepatology. 2010;51(1):142-153. doi:10.1002/hep.23247

70. Gao W, Jia Z, Tian Y, et al. HBx protein contributes to liver carcinogenesis by $\mathrm{H} 3 \mathrm{~K} 4 \mathrm{me} 3$ modification through stabilizing WD repeat domain 5 protein. Hepatology. 2020;71 (5):1678-1695. doi:10.1002/hep.30947

71. Yoo YG, Na TY, Seo HW, et al. Hepatitis B virus X protein induces the expression of MTA1 and HDAC1, which enhances hypoxia signaling in hepatocellular carcinoma cells. Oncogene. 2008;27(24):3405-3413. doi:10.1038/sj.onc.1211000

72. Salerno D, Chiodo L, Alfano V, et al. Hepatitis B protein HBx binds the DLEU2 lncRNA to sustain cccDNA and host cancer-related gene transcription. Gut. 2020;69(11):2016-2024. doi:10.1136/gutjnl-2019-319637

73. Aicher S, Kakkanas A, Cohen L, et al. Differential regulation of the Wnt/beta-catenin pathway by hepatitis $\mathrm{C}$ virus recombinants expressing core from various genotypes. Sci Rep. 2018;8 (1):11185. doi:10.1038/s41598-018-29078-2

74. Daud M, Rana MA, Husnain T, Ijaz B. Modulation of Wnt signaling pathway by hepatitis B virus. Arch Virol. 2017;162 (10):2937-2947. doi:10.1007/s00705-017-3462-6

75. Liu Y, Ye X, Zhang JB, et al. PROX1 promotes hepatocellular carcinoma proliferation and sorafenib resistance by enhancing beta-catenin expression and nuclear translocation. Oncogene. 2015;34(44):5524-5535. doi:10.1038/onc.2015.7 
76. Huang M, Chen C, Geng J, et al. Targeting KDM1A attenuates Wnt/beta-catenin signaling pathway to eliminate sorafenib-resistant stem-like cells in hepatocellular carcinoma. Cancer Lett. 2017;398:12-21. doi:10.1016/j.canlet.2017.03.038

77. Lin X, Li AM, Li YH, et al. Silencing MYH9 blocks HBX-induced GSK3beta ubiquitination and degradation to inhibit tumor stemness in hepatocellular carcinoma. Signal Transduct Target Ther. 2020;5(1):13. doi:10.1038/s41392-020-0111-4

78. Hsieh A, Kim HS, Lim SO, Yu DY, Jung G. Hepatitis B viral $\mathrm{X}$ protein interacts with tumor suppressor adenomatous polyposis coli to activate Wnt/beta-catenin signaling. Cancer Lett. 2011;300 (2):162-172. doi:10.1016/j.canlet.2010.09.018

79. Monga SP. Beta-catenin signaling and roles in liver homeostasis, injury, and tumorigenesis. Gastroenterology. 2015;148 (7):1294-1310. doi:10.1053/j.gastro.2015.02.056

80. Liu P, Cheng H, Roberts TM, Zhao JJ. Targeting the phosphoinositide 3-kinase pathway in cancer. Nat Rev Drug Discov. 2009;8(8):627-644. doi:10.1038/nrd2926

81. Chung TW, Lee YC, Ko JH, Kim CH. Hepatitis B virus X protein modulates the expression of PTEN by inhibiting the function of p53, a transcriptional activator in liver cells. Cancer Res. 2003;63 (13):3453-3458.

82. Ha HL, Yu DY. HBx-induced reactive oxygen species activates hepatocellular carcinogenesis via dysregulation of PTEN/Akt pathway. World J Gastroenterol. 2010;16(39):4932-4937. doi:10.3748/wjg.v16.i39.4932

83. Kim GW, Imam H, Khan M, et al. HBV-induced increased N6 methyladenosine modification of PTEN RNA affects innate immunity and contributes to HCC. Hepatology. 2020;73:533-547. doi:10.1002/hep.31313

84. Khattar E, Mukherji A, Kumar V. Akt augments the oncogenic potential of the $\mathrm{HBx}$ protein of hepatitis $\mathrm{B}$ virus by phosphorylation. FEBS J. 2012;279(7):1220-1230. doi:10.1111/ j.1742-4658.2012.08514.x

85. Chiu AP, Tschida BR, Sham TT, et al. HBx-K130M/V131I promotes liver cancer in transgenic mice via AKT/FOXO1 signaling pathway and arachidonic acid metabolism. Mol Cancer Res. 2019;17(7):1582-1593. doi:10.1158/1541-7786.MCR-18-1127

86. Chang WW, Su IJ, Chang WT, Huang W, Lei HY, Lei H-Y. Suppression of p38 mitogen-activated protein kinase inhibits hepatitis B virus replication in human hepatoma cell: the antiviral role of nitric oxide. J Viral Hepat. 2008;15(7):490-497. doi:10.1111/j.1365-2893.2007.00968.x

87. Kim SY, Kim H, Kim SW, et al. An effective antiviral approach targeting Hepatitis B virus with NJK14047, a novel and selective biphenyl amide p38 mitogen-activated protein kinase inhibitor. Antimicrob Agents Chemother. 2017;61(8). doi:10.1128/ AAC.00214-17.

88. Witt-Kehati D, Fridkin A, Alaluf MB, Zemel R, Shlomai A. Inhibition of pMAPK14 overcomes resistance to sorafenib in hepatoma cells with Hepatitis B virus. Transl Oncol. 2018;11 (2):511-517. doi:10.1016/j.tranon.2018.02.015

89. Liao B, Zhou H, Liang H, Li C. Regulation of ERK and AKT pathways by hepatitis B virus X protein via the Notch1 pathway in hepatocellular carcinoma. Int J Oncol. 2017;51(5):1449-1459. doi:10.3892/ijo.2017.4126

90. Li M, Zhou ZH, Sun XH, et al. Hepatitis B core antigen upregulates B7-H1 on dendritic cells by activating the AKT/ERK/P38 pathway: a possible mechanism of hepatitis B virus persistence. Lab Invest. 2016;96(11):1156-1164. doi:10.1038/ labinvest.2016.96

91. Valgimigli M, Valgimigli L, Trere D, et al. Oxidative stress EPR measurement in human liver by radical-probe technique. Correlation with etiology, histology and cell proliferation. Free Radic Res. 2002;36(9):939-948. doi:10.1080/ 107156021000006653
92. Fujita N, Sugimoto R, Ma N, et al. Comparison of hepatic oxidative DNA damage in patients with chronic hepatitis B and C. J Viral Hepat. 2008;15(7):498-507. doi:10.1111/j.13652893.2008.00972.x

93. Bolukbas C, Bolukbas FF, Horoz M, Aslan M, Celik H, Erel O. Increased oxidative stress associated with the severity of the liver disease in various forms of hepatitis B virus infection. BMC Infect Dis. 2005;5:95. doi:10.1186/1471-2334-5-95

94. Ivanov AV, Valuev-Elliston VT, Tyurina DA, et al. Oxidative stress, a trigger of hepatitis $\mathrm{C}$ and $\mathrm{B}$ virus-induced liver carcinogenesis. Oncotarget. 2017;8(3):3895-3932. doi:10.18632/ oncotarget.13904

95. Lee HR, Cho YY, Lee GY, You DG, Yoo YD, Kim YJ. A direct role for hepatitis $\mathrm{B}$ virus $\mathrm{X}$ protein in inducing mitochondrial membrane permeabilization. J Viral Hepat. 2018;25(4):412-420. doi:10.1111/jvh.12831

96. Lee YI, Hwang JM, Im JH, et al. Human hepatitis B virus-X protein alters mitochondrial function and physiology in human liver cells. J Biol Chem. 2004;279(15):15460-15471. doi:10.1074/jbc.M309280200

97. Xie H, Xie D, Zhang J, et al. ROS/NF-kappaB signaling pathway-mediated transcriptional activation of TRIM37 promotes HBV-associated hepatic fibrosis. Mol Ther Nucleic Acids. 2020;22:114-123. doi:10.1016/j.omtn.2020.08.014

98. Yuan K, Lei Y, Chen HN, et al. HBV-induced ROS accumulation promotes hepatocarcinogenesis through Snail-mediated epigenetic silencing of SOCS3. Cell Death Differ. 2016;23 (4):616-627. doi:10.1038/cdd.2015.129

99. Kensler TW, Wakabayashi N, Biswal S. Cell survival responses to environmental stresses via the Keap1-Nrf2-ARE pathway. Annu Rev Pharmacol Toxicol. 2007;47:89-116. doi:10.1146/annurev. pharmtox.46.120604.141046

100. Zhang HT, Chen GG, Hu BG, et al. Hepatitis B virus x protein induces autophagy via activating death-associated protein kinase. $J$ Viral Hepat. 2014;21(9):642-649. doi:10.1111/jvh.12191

101. Wang X, Lin Y, Liu S, et al. O-GlcNAcylation modulates HBV replication through regulating cellular autophagy at multiple levels. FASEB J. 2020;34(11):14473-14489. doi:10.1096/ fj.202001168RR

102. He Q, Song X, Huang Y, et al. Dexamethasone stimulates Hepatitis B Virus (HBV) replication through autophagy. Med Sci Monit. 2018;24:4617-4624. doi:10.12659/MSM.906250

103. Xie M, Yang Z, Liu Y, Zheng M. The role of HBV-induced autophagy in HBV replication and HBV related-HCC. Life Sci. 2018;205:107-112. doi:10.1016/j.lfs.2018.04.051

104. Li J, Liu Y, Wang Z, et al. Subversion of cellular autophagy machinery by hepatitis B virus for viral envelopment. J Virol. 2011;85(13):6319-6333. doi:10.1128/JVI.02627-10

105. Sir D, Tian Y, Chen WL, Ann DK, Yen TS, Ou JH. The early autophagic pathway is activated by hepatitis $\mathrm{B}$ virus and required for viral DNA replication. Proc Natl Acad Sci U S A. 2010;107 (9):4383-4388. doi:10.1073/pnas.0911373107

106. Lin $\mathrm{Y}, \mathrm{Wu} \mathrm{C}$, Wang $\mathrm{X}$, et al. Hepatitis B virus is degraded by autophagosome-lysosome fusion mediated by Rab7 and related components. Protein Cell. 2019;10(1):60-66. doi:10.1007/ s13238-018-0555-2

107. Lin Y, Wu C, Wang X, et al. Synaptosomal-associated protein 29 is required for the autophagic degradation of hepatitis $\mathrm{B}$ virus. FASEB J. 2019;33(5):6023-6034. doi:10.1096/fj.201801995RR

108. Rautou PE, Mansouri A, Lebrec D, Durand F, Valla D, Moreau R. Autophagy in liver diseases. J Hepatol. 2010;53(6):1123-1134. doi:10.1016/j.jhep.2010.07.006

109. Zhang H, Zhang Y, Zhu X, et al. DEAD box protein 5 inhibits liver tumorigenesis by stimulating autophagy via interaction with p62/SQSTM1. Hepatology. 2019;69(3):1046-1063. doi:10.1002/ hep. 30300 
110. Lan SH, Wu SY, Zuchini R, et al. Autophagy suppresses tumorigenesis of hepatitis B virus-associated hepatocellular carcinoma through degradation of microRNA-224. Hepatology. 2014;59 (2):505-517. doi:10.1002/hep.26659

111. Wu SY, Lan SH, Liu HS. Degradative autophagy selectively regulates CCND1 (cyclin D1) and MIR224, two oncogenic factors involved in hepatocellular carcinoma tumorigenesis. Autophagy. 2019;15(4):729-730. doi:10.1080/15548627.2019.1569918

112. Yan Y, Liu N, Lu L, et al. Autophagy enhances antitumor immune responses induced by irradiated hepatocellular carcinoma cells engineered to express hepatitis B virus X protein. Oncol Rep. 2013;30(2):993-999. doi:10.3892/or.2013.2531

113. Chen YY, Wang WH, Che L, et al. BNIP3L-dependent mitophagy promotes $\mathrm{HBX}$-induced cancer stemness of hepatocellular carcinoma cells via glycolysis metabolism reprogramming. Cancers (Basel). 2020;12(3).

114. Wang $\mathrm{MD}$, Wu $\mathrm{H}$, Huang $\mathrm{S}$, et al. $\mathrm{HBx}$ regulates fatty acid oxidation to promote hepatocellular carcinoma survival during metabolic stress. Oncotarget. 2016;7(6):6711-6726. doi:10.18632/oncotarget.6817

115. Chen SL, Zhang CZ, Liu LL, et al. A GYS2/p53 negative feedback loop restricts tumor growth in HBV-related hepatocellular carcinoma. Cancer Res. 2019;79(3):534-545. doi:10.1158/00085472.CAN-18-2357

116. Chen W, Jiang J, Gong L, et al. Hepatitis B virus $\mathrm{P}$ protein initiates glycolytic bypass in HBV-related hepatocellular carcinoma via a FOXO3/miRNA-30b-5p/MINPP1 axis. J Exp Clin Cancer Res. 2021;40(1):1. doi:10.1186/s13046-020-01803-8

117. Zhou L, He R, Fang P, et al. Hepatitis B virus rigs the cellular metabolome to avoid innate immune recognition. Nat Commun 2021;12(1):98. doi:10.1038/s41467-020-20316-8

118. Fisicaro P, Boni C, Barili V, Laccabue D, Ferrari C. Strategies to overcome HBV-specific T cell exhaustion: checkpoint inhibitors and metabolic re-programming. Curr Opin Virol. 2018;30:1-8. doi:10.1016/j.coviro.2018.01.003

119. Kapil S, Duseja A, Sharma BK, et al. Small intestinal bacterial overgrowth and toll-like receptor signaling in patients with non-alcoholic fatty liver disease. $J$ Gastroenterol Hepatol. 2016;31(1):213-221. doi:10.1111/jgh.13058

120. Zeng Y, Chen S, Fu Y, et al. Gut microbiota dysbiosis in patients with hepatitis B virus-induced chronic liver disease covering chronic hepatitis, liver cirrhosis and hepatocellular carcinoma. $J$ Viral Hepat. 2020;27(2):143-155. doi:10.1111/jvh.13216

121. Liu Q, Li F, Zhuang Y, et al. Alteration in gut microbiota associated with hepatitis B and non-hepatitis virus related hepatocellular carcinoma. Gut Pathog. 2019;11:1. doi:10.1186/s13099-0180281-6

122. Toffanin S, Cornella H, Harrington A, Llovet JM. HCC is promoted by bacterial translocation and TLR-4 signaling: a new paradigm for chemoprevention and management. Hepatology. 2012;56(5):1998-2000. doi:10.1002/hep.26080

123. Zheng B, Yang Y, Han Q, Yin C, Pan Z, Zhang J. STAT3 directly regulates NKp46 transcription in $\mathrm{NK}$ cells of $\mathrm{HBeAg-negative}$ CHB patients. J Leukoc Biol. 2019;106(4):987-996. doi:10.1002/ JLB.2A1118-421R

124. Sun C, Sun H, Zhang C, Tian Z. NK cell receptor imbalance and NK cell dysfunction in $\mathrm{HBV}$ infection and hepatocellular carcinoma. Cell Mol Immunol. 2015;12(3):292-302. doi:10.1038/cmi.2014.91

125. Xu D, Han Q, Hou Z, Zhang C, Zhang J. miR-146a negatively regulates NK cell functions via STAT1 signaling. Cell Mol Immunol. 2017;14(8):712-720. doi:10.1038/cmi.2015.113

126. Yu X, Lan P, Hou X, et al. HBV inhibits LPS-induced NLRP3 inflammasome activation and IL-1beta production via suppressing the NF-kappaB pathway and ROS production. J Hepatol. 2017;66 (4):693-702. doi:10.1016/j.jhep.2016.12.018
127. Faure-Dupuy S, Delphin M, Aillot L, et al. Hepatitis B virus-induced modulation of liver macrophage function promotes hepatocyte infection. $J$ Hepatol. 2019;71(6):1086-1098. doi:10.1016/j.jhep.2019.06.032

128. Raziorrouh B, Schraut W, Gerlach T, et al. The immunoregulatory role of CD244 in chronic hepatitis B infection and its inhibitory potential on virus-specific CD8+ T-cell function. Hepatology. 2010;52(6):1934-1947. doi:10.1002/hep.23936

129. Tjwa ET, van Oord GW, Hegmans JP, Janssen HL, Woltman AM. Viral load reduction improves activation and function of natural killer cells in patients with chronic hepatitis B. J Hepatol. 2011;54(2):209-218. doi:10.1016/j.jhep.2010.07.009

130. Fisicaro P, Barili V, Montanini B, et al. Targeting mitochondrial dysfunction can restore antiviral activity of exhausted HBV-specific CD8 T cells in chronic hepatitis B. Nat Med. 2017;23(3):327-336. doi:10.1038/nm.4275

131. Zong L, Peng H, Sun C, et al. Breakdown of adaptive immunotolerance induces hepatocellular carcinoma in HBsAg-tg mice. Nat Commun. 2019;10(1):221. doi:10.1038/s41467-018-08096-8

132. Liu X, He L, Han J, et al. Association of neutrophil-lymphocyte ratio and $\mathrm{T}$ lymphocytes with the pathogenesis and progression of HBV-associated primary liver cancer. PLoS One. 2017;12(2): e0170605. doi:10.1371/journal.pone.0170605

133. Tajiri K, Baba H, Kawai K, et al. Neutrophil-to-lymphocyte ratio predicts recurrence after radiofrequency ablation in hepatitis B virus infection. $J$ Gastroenterol Hepatol. 2016;31 (7):1291-1299. doi:10.1111/jgh.13287

134. Yang P, Li QJ, Feng Y, et al. TGF-beta-miR-34a-CCL22 signaling-induced Treg cell recruitment promotes venous metastases of HBV-positive hepatocellular carcinoma. Cancer Cell. 2012;22(3):291-303. doi:10.1016/j.ccr.2012.07.023

135. Li K, Liu H, Guo T. Th17/Treg imbalance is an indicator of liver cirrhosis process and a risk factor for HCC occurrence in HBV patients. Clin Res Hepatol Gastroenterol. 2017;41(4):399-407. doi:10.1016/j.clinre.2016.12.004

136. Liu X, Li M, Wang X, et al. PD-1(+) TIGIT(+) CD8(+) T cells are associated with pathogenesis and progression of patients with hepatitis B virus-related hepatocellular carcinoma. Cancer Immunol Immunother. 2019;68(12):2041-2054. doi:10.1007/ s00262-019-02426-5

137. Lim CJ, Lee YH, Pan L, et al. Multidimensional analyses reveal distinct immune microenvironment in hepatitis B virus-related hepatocellular carcinoma. Gut. 2019;68(5):916-927. doi:10.1136/gutjnl-2018-316510

138. Li S, Li S, Wu S, Chen L. Exosomes modulate the viral replication and host immune responses in HBV infection. Biomed Res Int. 2019;2019:2103943.

139. Kakizaki M, Yamamoto Y, Yabuta S, Kurosaki N, Kagawa T, Kotani A. The immunological function of extracellular vesicles in hepatitis B virus-infected hepatocytes. PLoS One. 2018;13(12): e0205886. doi:10.1371/journal.pone.0205886

140. Kapoor NR, Chadha R, Kumar S, Choedon T, Reddy VS, Kumar V. The HBx gene of hepatitis B virus can influence hepatic microenvironment via exosomes by transferring its mRNA and protein. Virus Res. 2017;240:166-174. doi:10.1016/j. virusres.2017.08.009

141. Yang Y, Han Q, Hou Z, Zhang C, Tian Z, Zhang J. Exosomes mediate hepatitis B virus (HBV) transmission and NK-cell dysfunction. Cell Mol Immunol. 2017;14(5):465-475. doi: $10.1038 / \mathrm{cmi} .2016 .24$

142. Shi Y, Du L, Lv D, et al. Exosomal interferon-induced transmembrane protein 2 transmitted to dendritic cells inhibits interferon alpha pathway activation and blocks anti-Hepatitis B virus efficacy of exogenous interferon alpha. Hepatology. 2019;69 (6):2396-2413. doi:10.1002/hep.30548 
143. Liu DX, Li PP, Guo JP, et al. Exosomes derived from HBV-associated liver cancer promote chemoresistance by upregulating chaperone-mediated autophagy. Oncol Lett. 2019;17 (1):323-331. doi:10.3892/ol.2018.9584

144. Petersen J, Thompson AJ, Levrero M. Aiming for cure in HBV and HDV infection. J Hepatol. 2016;65(4):835-848. doi:10.1016/ j.jhep.2016.05.043

145. Han Q, Hou Z, Yin C, Zhang C, Zhang J. 5'-triphosphate siRNA targeting $\mathrm{HBx}$ elicits a potent anti-HBV immune response in pAAV-HBV transfected mice. Antiviral Res. 2019;161:36-45. doi:10.1016/j.antiviral.2018.11.006

146. Yao Z, Qiao Y, Li X, et al. Exosomes exploit the virus entry machinery and pathway to transmit alpha interferon-induced antiviral activity. J Virol. 2018;92(24). doi:10.1128/JVI.01578-18.

147. Li J, Liu K, Liu Y, et al. Exosomes mediate the cell-to-cell transmission of IFN-alpha-induced antiviral activity. Nat Immunol. 2013;14(8):793-803. doi:10.1038/ni.2647
148. Jesus S, Soares E, Cruz MT, Borges O. Exosomes as adjuvants for the recombinant hepatitis B antigen: first report. Eur J Pharm Biopharm. 2018;133:1-11. doi:10.1016/j.ejpb.2018.09.029

149. Horng JH, Lin WH, Wu CR, et al. HBV X protein-based therapeutic vaccine accelerates viral antigen clearance by mobilizing monocyte infiltration into the liver in HBV carrier mice. J Biomed Sci. 2020;27(1):70. doi:10.1186/s12929-020-00662-x

150. Zhao HJ, Han QJ, Wang G, et al. Poly I:C-based rHBVvac therapeutic vaccine eliminates $\mathrm{HBV}$ via generation of HBV-specific CD8(+) effector memory T cells. Gut. 2019;68 (11):2032-2043. doi:10.1136/gutjnl-2017-315588

151. Wang W, Zhou X, Bian Y, et al. Dual-targeting nanoparticle vaccine elicits a therapeutic antibody response against chronic hepatitis B. Nat Nanotechnol. 2020;15(5):406-416. doi:10.1038/ s41565-020-0648-y

\section{Publish your work in this journal}

The Journal of Hepatocellular Carcinoma is an international, peerreviewed, open access journal that offers a platform for the dissemination and study of clinical, translational and basic research findings in this rapidly developing field. Development in areas including, but not limited to, epidemiology, vaccination, hepatitis therapy, pathology and molecular tumor classification and prognostication are all considered for publication. The manuscript management system is completely online and includes a very quick and fair peer-review system, which is all easy to use. Visit http://www.dovepress.com/ testimonials.php to read real quotes from published authors. 